\title{
Analysis of association among clinical features and shorter leukocyte telomere length in mitochondrial diabetes with m.3243A > G mitochondrial DNA mutation
}

Mei-Cen Zhou' ${ }^{1}$, Rui Min ${ }^{1}$, Jian-Jun Ji ${ }^{2}$, Shi Zhang ${ }^{3}$, An-Li Tong ${ }^{1}$, Jian-ping Xu' ${ }^{1}$ Zeng-Yi Li ${ }^{4}$, Hua-Bing Zhang ${ }^{1}$ and $\mathrm{Yu}-\mathrm{Xiu} \mathrm{Li}{ }^{1 *}$

\begin{abstract}
Background: Mitochondrial diabetes is a kind of rare diabetes caused by monogenic mutation in mitochondia. The study aimed to summarize the clinical phenotype profiles in mitochondrial diabetes withm.3243A $>\mathrm{G}$ mitochondrial DNA mutation and to investigate the mechanism in this kind of diabetes by analyzing the relationship among clinical phenotypes and peripheral leukocyte DNA telomere length.

Methods: Fifteen patients with maternally inherited diabetes in five families were confirmed as carrying the m.3243A>G mitochondrial DNA mutation. One hundred patients with type 2 diabetes and one hundred healthy control subjects were recruited to participate in the study. Sanger sequencing was used to detect the m.3243A>G mitochondrial DNA mutation. The peak height $\mathrm{G} / \mathrm{A}$ ratio in the sequence diagram was calculated. Real-time polymerase chain reaction (PCR) was used to measure telomere length.

Results: The patients with mitochondrial diabetes all had definite maternally inherited history, normal BMI $\left(19.5 \pm 2.36 \mathrm{~kg} / \mathrm{m}^{2}\right)$, early onset of diabetes (35.0 \pm 14.6 years) and deafness. The peak height G/A ratio correlated significantly and negatively with the age at onset of diabetes ( $\leqq 25$ years, $61.6 \pm 20.17 \%$; $25-45$ years, $16.59 \pm 8.64 \% ;>45$ years, $6.37 \pm 0.59 \% ; p=0.000$ ). Telomere length was significantly shorter among patients with mitochondrial diabetes and type 2 diabetes than in the control group (1.28 \pm 0.54 vs. $1.14 \pm 0.43$ vs. $1.63 \pm 0.61 ; p=0.000)$. However, there was no significant difference between patients with mitochondrial diabetes and those with type 2 diabetes. There was no correlation between telomere length and the peak height $\mathrm{G} / \mathrm{A}$ ratio.
\end{abstract}

Conclusion: Deafness with definite maternal inheritance and normal BMI, associated with elevated blood lactic acid and encephalomyopathy, for the most part, suggest the diagnosis of mitochondrial diabetes. The peak height G/A ratio could reflect the spectrum of age at onset of the disease. Telomere length was shorter in patients with mitochondrial diabetes and those with type 2 diabetes, which suggests that the shorter telomere length is likely involved in the pathogenesis of diabetes but is not specific for this kind of diabetes.

Keywords: Mitochondrial diabetes, m.3243A>G mitochondrial DNA mutation, Clinical features, Leukocyte telomere length

\footnotetext{
*Correspondence: liyuxiu@medmail.com.cn

'Department of Endocrinology, Key Laboratory of Endocrinology, Ministry of

Health, Peking Union Medical College Hospital, Beijing 100730, China

Full list of author information is available at the end of the article
}

Ciomed Central (c) 2015 Zhou et al. Open Access This article is distributed under the terms of the Creative Commons Attribution 4.0 International License (http://creativecommons.org/licenses/by/4.0/, which permits unrestricted use, distribution, and reproduction in any medium, provided you give appropriate credit to the original author(s) and the source, provide a link to the Creative Commons license, and indicate if changes were made. The Creative Commons Public Domain Dedication waiver (http://creativecommons.org/publicdomain/zero/1.0/) applies to the data made available in this article, unless otherwise stated. 


\section{Background}

Mitochondrial diabetes is a kind of rare diabetes caused by monogenic mutation in mitochondria, which was first described in 1992, results from an A to G substitution at nucleotide position $3243(\mathrm{~m} .3243 \mathrm{~A}>\mathrm{G}$ mitochondrial DNA mutation) of the mitochondrial gene encoding tRNA $^{\text {Leu }}$ [1-4]. Eighty-five percent of mitochondrial diabetes cases are associated with $\mathrm{m} .3243 \mathrm{~A}>\mathrm{G}$ mitochondrial DNA mutation [5], and although other mitochondrial DNA point mutations have been associated with mitochondrial diabetes, these occurrences are extremely rare [6]. Because mitochondria are distinct organelles in the cytoplasm, its inheritance is only maternal, and mitochondrial DNA mutations have different heteroplasmy levels that vary among different tissues in a single individual; hence, there is a wide range of clinical phenotypes and mitochondrial diabetes is frequently misdiagnosed as either type 1 or type 2 diabetes, depending on the clinical presentation [5].

DNA telomeres, which are specific DNA-protein structures in the terminal regions of chromosomes, are a biomarker of biological aging and can reflect the lifespan of cells [7]. Telomere shortening has been observed in subjects with type 2 diabetes or impaired glucose tolerance, for example, in Chinese [8], Afro-Caribbean [9], Arabic and Caucasian [10] populations. Many factors are involved in telomere shortening; for instance, reactive oxidative species (ROS) as by-products of mitochondrial oxidative phosphorylation (OXPHOS) play an important role in telomere shortening [11-13]. Mutations in mitochondrial DNA have an impact on the mitochondrial function of the pancreas among patients with mitochondrial diabetes. However, whether the change in the mitochondrial function in patients with mitochondrial diabetes can affect DNA telomere length is still unknown. In this study, we hypothesize that telomere length shortening exists in the beta cells of mitochondrial diabetes, which can shorten the lifespan of beta cells. Exploring the pathogenesis by investigating the relationship between changes in mitochondrial function and telomere length can provide new insight.

The present study aimed to summarize the profiles of clinical phenotypes in fifteen patients with mitochondrial diabetes from five different families and to investigate the mechanism of mitochondrial diabetes by analyzing the relationship among clinical phenotypes and peripheral leukocyte DNA telomere length in blood.

\section{Methods}

\section{Study subjects}

According to the inclusion criteria for this study, forty subjects with diabetes in Peking Union Medical College were included between 2007 and 2014. The inclusion criteria were as follows: (1) age at the diagnosis of diabetes $\leq 40$ years old; (2) $\mathrm{BMI} \leq 24 \mathrm{~kg} / \mathrm{m}^{2}$; (3) negative autoimmune diabetes antibodies: insulin autoantibody IAA (-), islet cell antibody ICA (-), glutamate decarboxylase antibody GAD (-), and protein-tyrosinephosphatase antibody IA2 (-); (4) maternal family history of diabetes; (5) deafness; (6) elevated serum lactic acid level; and (7) encephalomyopathy. Items (1),(2),(3),(4)are necessary items, with or without items (5,(6),(7). Five patients were confirmed as carrying the m.3243A>G mitochondrial DNA mutation, these patients were defined as mitochondrial diabetes. By further screening the family members of the five probands, a total of fifteen patients with mitochondrial diabetes (age range: $17 \sim 68$ years-old) were confirmed. One hundred patients with type 2 diabetes (age range: $22 \sim 67$ years-old) and one hundred healthy individuals without diabetes (age range: $19 \sim 65$ years-old) were recruited to participate in the study and were matched according to age and gender. The study protocol was approved by the Ethics Committee of Peking Union Medical College Hospital. The subjects signed an informed consent form and all the subjects provided written informed consent for the publication of their clinical details. We also obtained the written informed consent from the guardians of the only one subjects who was 17 years-old. The study protocol was approved by the Ethics Committee of Peking Union Medical College Hospital.

\section{M.3243A>G mitochondrial DNA mutation screening method}

Genomic DNA from peripheral lymphocytes was isolated using the QIAamp DNA Mini Kit (QIAGEN, Germany). The PCR assay was designed to detect the $\mathrm{mt}$ 3243A to $\mathrm{G}$ mutation using a direct PCR. The following two primers were used in one reaction tube:

\section{Forward: 5'-AGCGCCTTCCCCCGTAAATGA-3', Reverse: 5'-AGAATGATGGCTAGGGTGACTTC-3'.}

The primers were designed using Oligo 6.0. Nucleotides $3160-3620$ of mt DNA were amplified. Each PCR product was segregated using agarose gel electrophoresis and purified using the gel extraction method before being sequenced in an ABI3730xl sequencer using the forward PCR primer. The sequencing data were aligned using BLAST Search Genome (http://genome.ucsc.edu). Each sample was sequenced twice.

\section{The peak height $\mathrm{G} / \mathrm{A}$ ratio in the sequence diagram}

The peak height G/A ratio in the sequence diagram was calculated according to the mean value of the sequences (Each sample was sequenced twice). The peak height G/A ratio was defined as the peak height $\mathrm{A}$ was divided by the peak height $\mathrm{G}$ as show in Fig. 1. 


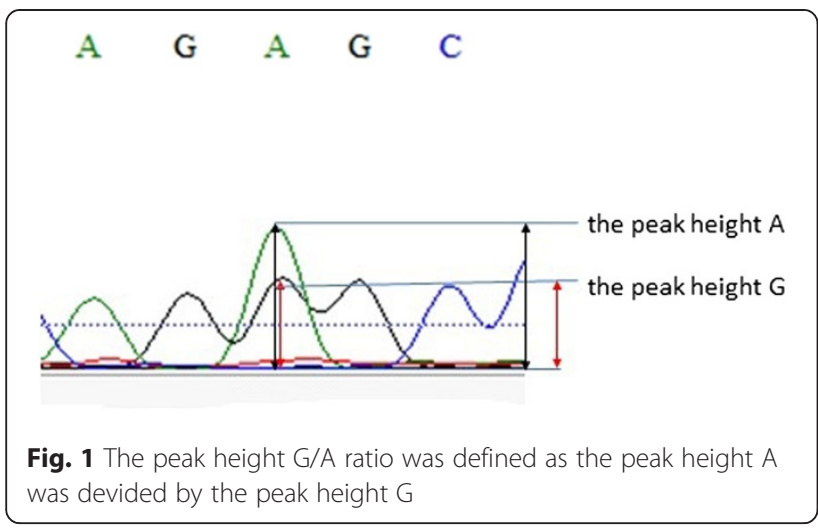

Leukocyte DNA telomere length measurement

Telomere length was determined as the relative ratio of telomere repeat copy number to the single copy number (T/S) using the novel monochrome multiplex quantitative PCR protocol described by Cawthon [14]. Telomere primer sequences were as follows:

\section{telg : 5'-ACACTAAGGTTTGGGTTTGGGTTTGGGT TTGGGTTAGTGT-3', telc : 5'-TGTTAGGTATCCCTATCCCTATCCCTATCC CTATCCCTAACA-3',}

and albumin was employed as the single copy gene reference using primers modified with the addition of 5 '-GC clamp to shift their melting temperature:

\section{albu : 5'-CGGCGGCGGGCGGCGCGGGCTGGGCGG AAATGCTGCACAGAATCCTTG-3'; albd : 5'-GCCCGGCCCGCCGCGCCCGTCCCGCCG GAAAAGCATGGTCGCCTGTT-3'.}

The reagent components and final concentrations were $900 \mathrm{nM}$ each primer (IDT), $1 \times$ AmpliTaq Buffer II, $3 \mathrm{mM} \mathrm{MgCl} 2,0.2 \mathrm{mM}$ per dNTP, $1 \mathrm{mM}$ DTT, $1 \mathrm{M}$ betaine, $0.75 \times$ SYBR Green I and 0.625U AmpliTaq Gold DNA polymerase. Human genomic DNA samples, $5 \mathrm{ng}$ to $70 \mathrm{ng}$, were used to generate two standard curves for each PCR plate (five concentrations with a high level of $150 \mathrm{ng}$ and a low level of $1.85 \mathrm{ng}$ per reaction). Thermal cycling: 1 cycle of $15 \mathrm{~min}$ at $95^{\circ} \mathrm{C} ; 2$ cycles of $15 \mathrm{~s}$ at $94{ }^{\circ} \mathrm{C}, 15 \mathrm{~s}$ at $49^{\circ} \mathrm{C}$; and 32 cycles of $15 \mathrm{~s}$ at $94{ }^{\circ} \mathrm{C}, 10 \mathrm{~s}$ at $62{ }^{\circ} \mathrm{C}, 15 \mathrm{~s}$ at $74{ }^{\circ} \mathrm{C}$ with signal acquisition, $10 \mathrm{~s}$ at $84{ }^{\circ} \mathrm{C}$, and $15 \mathrm{~s}$ at $88^{\circ} \mathrm{C}$ with signal acquisition. Bio-Rad CFX Manger software automatically estimated the value for each sample $\mathrm{T}$ (telomere) and S(single copy gene) using standard curve. Standard curve efficiencies for both primer sets were above $90 \%$, and regression coefficients were at least 0.99 in all PCR runs. The within-plate and between-plate \% coefficient of variation(\% CV), which is based on the ratio of the standard deviation across replicates to the mean, were $18 \%$ and $7 \%$, respectively. For study samples, the with-plate \% CV ranged from $8.2-14.3 \%$.

\section{Statistical analyses}

The statistical analyses were performed using SPSS 17.0. Parameters not normally distributed were transformed. The variables were expressed as the mean \pm SD. Statistical analyses were performed with ANOVA followed by Bonferroni's post hoc pairwise comparisons. The multivariable linear regression analysis was used to test the relationship between variables and the risk factors.

\section{Results}

1. Clinical features in mitochondrial diabetes Five patients with mitochondrial diabetes from five different families were confirmed by m.3243A>G mitochondrial DNA mutation screening from forty suspected patients with mitochondrial diabetes; screening rate was $12.5 \%$. In the other maternal members of the five patients from the five families, there were eleven subjects with $\mathrm{m} .3243 \mathrm{~A}>\mathrm{G}$ mitochondrial DNA mutation among the eleven subjects, ten subjects suffered from mitochondrial diabetes, only one subject had mutation without any clinical presentation. Therefore, in total, there were fifteen patients with mitochondrial diabetes in the five families (Fig. 2). The mean age at the diagnosis of diabetes the five probands was $23.1 \pm 8.2$ years, and the onset of impaired hearing loss was before the diagnosis of diabetes. The five probands were all female; two of them had oligomenorrhea, their follicle stimulating hormone(FSH) and luteinizing hormone(LH)level was below the normal range (Table 1). At the onset of mitochondrial diabetes, the mean age of the fifteen patients was $35.0 \pm 14.6$ years, their BMI was $19.5 \pm 2.36\left(\mathrm{~kg} / \mathrm{m}^{2}\right)$, and one patient presented acutely with ketoacidosis-related type 1 diabetes, while the others presented insidiously with symptoms similar to type 2 diabetes. The general and specific clinical features of the 15 patients with mitochondrial diabetes are shown in Tables 2 and 3, respectively.

2. Comparison of telomere length among patients with mitochondrial diabetes and type 2 diabetes and healthy controls

The ages were matched among the three groups, and the duration of diabetes was matched between those with mitochondrial diabetes and those with type 2 diabetes. There was a significant difference in BMI among the three groups. Peripheral blood leukocyte DNA telomere length was significantly shorter in patients with mitochondrial diabetes and 


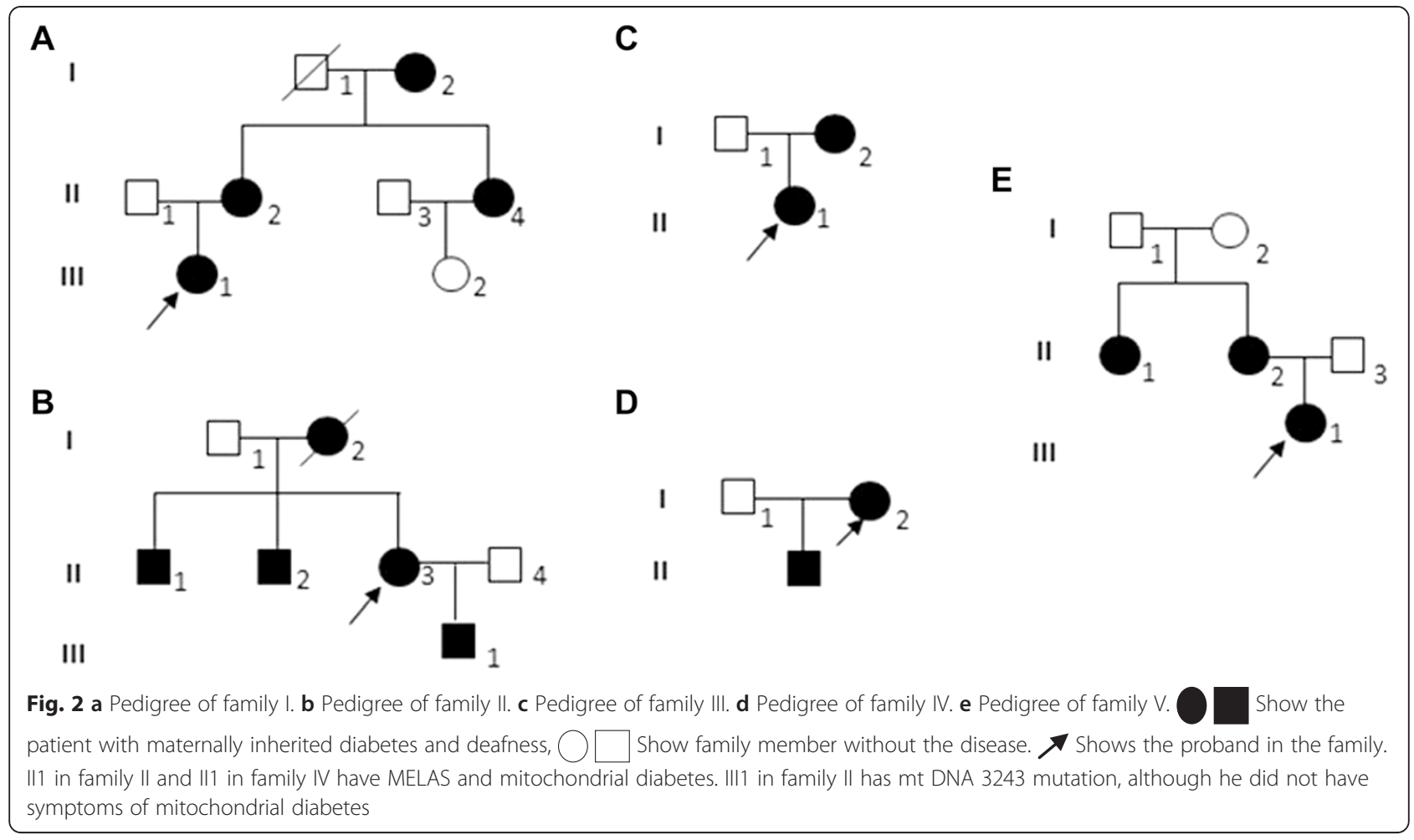

type 2 diabetes than in healthy controls; however, there was no significant difference between those with mitochondrial diabetes and those with type 2 diabetes (Table 4).

3. Correlation analysis between $\mathrm{m} .3243 \mathrm{~A}>\mathrm{G}$ mitochondrial DNA mutation (the peak height G/A ratio) and onset age of mitochondrial diabetes The peak height G/A ratio in the sequence diagram was calculated. The peak height G/A ratio was significantly different according to the age at the diagnosis of diabetes ( $\leq 25$ years, 25-45 years, and $>45$ years) (Table 5 ) and was negatively associated with the age at the diagnosis of diabetes after adjusting the age, BMI $(r=-0.891 ; p<0.001)$.

4. Correlation between telomere length and m.3243A>G mitochondrial DNA mutation (the peak height G/A ratio) and diabetes-related parameters

Table 1 Blood gonadal hormone levels in 2 patients with mitochondrial diabetes combined with oligomenorrhea

\begin{tabular}{llccccc}
\hline & $\begin{array}{l}\text { Age } \\
(\text { year })\end{array}$ & $\begin{array}{l}\mathrm{BMl} \\
\left(\mathrm{kg} / \mathrm{m}^{2}\right)\end{array}$ & $\begin{array}{l}\mathrm{FSH} \\
(\mathrm{m} / \mathrm{U} / \mathrm{L})\end{array}$ & $\begin{array}{l}\mathrm{LH} \\
(\mathrm{m} / \mathrm{U} / \mathrm{L})\end{array}$ & $\begin{array}{l}\mathrm{T} \\
(\mathrm{nmol} / \mathrm{L})\end{array}$ & $\begin{array}{l}\mathrm{E2} \\
(\mathrm{pmol} / \mathrm{L})\end{array}$ \\
\hline III1 (P:I) & 18 & 17.4 & 5.5 & 3.9 & 1.7 & 355.25 \\
II1 (P:III) & 26 & 21.7 & 1.2 & 0.21 & 3 & 28.7
\end{tabular}

P I-V represent family I-V, Age age at onset of oligomenorrhea, FSH follicle stimulating hormone, $L H$ luteinizing hormone, $T$ testosterone, $E 2$ estradiol
There was no significant relationship between peripheral blood leukocyte DNA telomere length and the peak height G/A ratio after adjusting age fasting glucose, insulin, C-peptide, HbA1c, HOMA-IR, and HOMA-IS. Fasting glucose, insulin, C-peptide, HbA1c, HOMA-IR, and HOMA-IS were not significantly related to DNA telomere length (Table 6).

Table 2 General clinical features of mitochondrial diabetes

\begin{tabular}{ll}
\hline & Mitochondrial diabetes $(n=15)$ \\
\hline Age (year) & $35.0 \pm 14.6$ \\
Gender (F/M) & $12: 3$ \\
Disease Duration (year) & $4.00 \pm 2.54$ \\
BMl (kg/m²) & $19.5 \pm 2.36$ \\
HbA1c (\%) & $6.42 \pm 1.01$ \\
Fasting blood glucose (mmol/L) & $7.75 \pm 2.03$ \\
Fasting insulin ( $\mu$ IU/ml) & $5.23 \pm 3.26$ \\
Fasting C-peptide (ng/ml) & $0.53 \pm 0.37$ \\
HOMA-IR & $1.63 \pm 0.81$ \\
HOMA-IS & $0.03 \pm 0.02$ \\
Diabetes treatment & $7: 8$ \\
(Insulin: oral hypoglycemic medication) & $(5$ probands all received \\
& insulin therapy)
\end{tabular}

BMI body mass index, HOMA-IR fasting plasma glucose $(\mathrm{mmol} / \mathrm{L}){ }^{*}$ fasting insulin $(\mu \mathrm{lU} / \mathrm{ml}) / 22.5$, HOMA-IS $1 /$ fasting plasma glucose $(\mathrm{mmol} / \mathrm{L}) *$ fasting insulin $(\mu \mathrm{lU} / \mathrm{ml})$ 
Table 3 Specific clinical features in mitochondrial diabetes $(n=15)$

\begin{tabular}{|c|c|c|c|c|c|c|c|c|}
\hline & Family member & $\begin{array}{l}\text { Age at } \\
\text { diagnosis (year) }\end{array}$ & $\begin{array}{l}\mathrm{BMl} \\
(\mathrm{kg} / \mathrm{m} 2)\end{array}$ & $\begin{array}{l}\text { Autoimmune } \\
\text { diabetes antibodies }\end{array}$ & Deafness & $\begin{array}{l}\text { Fasting/postprandial } \\
\text { elevated blood lactate }\end{array}$ & Encephalomyopathy & $\begin{array}{l}\text { The peak height } \\
\text { G/A ratio\% }\end{array}$ \\
\hline 1 & II1 (P:I) & 68 & 18.4 & ND & + & ND & - & 5.9 \\
\hline 2 & $\| 2$ & 49 & 23.4 & IAA (-)、ICA (-), GAD (-) & + & ND & - & 14 \\
\hline 3 & $\| 4$ & 48 & 16.8 & $\operatorname{IAA}(-) 、 \operatorname{ICA}(-), G A D(-)$ & + & ND & - & 14.9 \\
\hline 4 & 1111 & 18 & 18.7 & IAA (-)、ICA (-)、GAD (-) & + & - & - & 83.3 \\
\hline 5 & $12(P: \|)$ & 25 & 17.4 & ND & + & ND & - & 31.6 \\
\hline 6 & $\| 1$ & 31 & 21.2 & ND & + & + & + & 29.1 \\
\hline 7 & 112 & 43 & 20.1 & ND & + & ND & - & 8.2 \\
\hline 8 & $\| 3$ & 38 & 19 & IAA (-)、ICA (-)、GAD (-) & + & ND & - & 27.6 \\
\hline 9 & $12(P:|| \mid)$ & 43 & 18.4 & ND & + & ND & - & 8 \\
\hline 10 & $\| 1$ & 17 & 18.3 & IAA (-)、ICA (-)、GAD (-) & + & ND & - & 65 \\
\hline 11 & $12(P: I V)$ & 33 & 16.7 & IAA (-)、ICA (-)、GAD (-) & + & - & - & 29 \\
\hline 12 & $\| 1$ & 24 & 21.7 & ND & + & + & + & 27.1 \\
\hline 13 & $\| 1(P: V)$ & 26 & 24.9 & ND & + & ND & - & 34.5 \\
\hline 14 & 112 & 46 & 19.1 & ND & + & ND & - & 15.2 \\
\hline 15 & \|\| 1 & 17 & 18.4 & IAA (-)、ICA (-)、GAD (-) & + & ND & - & 63.6 \\
\hline
\end{tabular}

For the structure of the five- mitochondrial diabetes pedigree, see Fig. 1. P, I-V represent family I-V.;ND represents undetected;-, negative; +, positive. The peak height $\mathrm{G} / \mathrm{A}$ ratio, $\mathrm{m} .3243 \mathrm{~A}>\mathrm{G}$ mitochondrial DNA mutation peak height $\mathrm{G}$ to $\mathrm{A}$ ratio

\section{Discussion}

Patients with mitochondrial diabetes generally exhibit heteroplasmy levels of between $1 \%$ and $40 \%$ with regard to $\mathrm{m} .3243 \mathrm{~A}>\mathrm{G}$ mitochondrial DNA mutation in the blood [6]; however, heteroplasmy levels may vary in different tissues in a single individual. Although blood generally contains the lowest heteroplasmy levels $[15,16]$, detecting $\mathrm{m} .3243 \mathrm{~A}>\mathrm{G}$ mitochondrial DNA mutation in blood is used as a simple and widely available screening method. The present study screened m.3243A $>$ G mitochondrial DNA mutation in forty patients with suspected mitochondrial diabetes, five patients were confirmed to have the disease; the screening rate was $12.5 \%$, which was considerably higher than $1.69 \%$ (the screening rate in patients diagnosed with type 2 diabetes, as reported by Xiang et al. [17]). This result suggested that targeted screening in patients with suspected mitochondrial diabetes (combined with early onset of diabetes and normal BMI) could improve the diagnosis of mitochondrial diabetes.

Mitochondrial diabetes is frequently misdiagnosed as either type 1 or type 2 diabetes depending on the age of the patients and the mode of presentation. In the present study, patients with mitochondrial diabetes had a definite maternal history of diabetes; four out of five probands represented the second or third generation with diabetes in the family, which suggests that maternal history of diabetes plays an important role in the diagnosis. The mean age at the onset of diabetes was 35 yearsold, ranging from 17 years to 68 years; however, the age at onset for the proband in each family was relatively young, with normal BMI, accompanied by different degrees of deafness in the high-frequency domain. In the study, all the patients with mitochondrial diabetes carrying m.3243A $>$ G mitochondrial DNA mutation had deafness, suggesting the strong association between mitochondrial diabetes and hearing loss, which was in accordance with Mancuso M, et al. [18]. Several female patients had oligomenorrhea caused by idiopathic hypogonadotropic hypogonadism, which suggests that mitochondria dysfunction could be involved in pituitary function, leading to idiopathic hypogonadotropic hypogonadism. In this study, even in the same family, the clinical presentations were different; the progress of diabetes was not consistent;

Table 4 Comparison of age, duration of diabetes, BMI, and telomere length

\begin{tabular}{lccc}
\hline & Mitochondrial diabetes $(n=15)$ & T2DM $(n=100)$ & Healthy controls $(n=100)$ \\
\hline Age (year) & $35.2 \pm 19.1$ & $42.2 \pm 14.3$ & $38.3 \pm 10.3$ \\
Duration of diabetes (year) & $4.0 \pm 2.7$ & $4.8 \pm 3.5$ & 0.070 \\
BMl $\left(\mathrm{kg} / \mathrm{m}^{2}\right)$ & $19.5 \pm 2.36$ & $24.3 \pm 2.4$ & $21.2 \pm 1.4$ \\
Telomere length & $1.28 \pm 0.54$ & $1.14 \pm 0.43$ & $0.000^{* * *}$ \\
\hline
\end{tabular}

${ }_{* * *}^{*} p<0.001$. There was a significant difference in BMI and telomere length among the three groups 
Table 5 m.3243A>G mitochondrial DNA mutation the peak height $G$ to $A$ ratio among different ages at onset of mitochondrial diabetes

\begin{tabular}{llll}
\hline Age of onset (year) $(n=15)$ & $\leq 25(n=5)$ & $25-45(n=6)$ & $>45(n=4)$ \\
\hline The peak height G to A & $61.60 \pm 20.17^{* *}$ & $16.59 \pm 8.64^{* *}$ & $6.37 \pm 0.59^{* *}$
\end{tabular}
ratio

${ }^{* *} p<0.01$. There was a significant difference among different ages at onset of mitochondrial diabetes

several patients presented acutely with ketoacidosisrelated type 1 diabetes; and other patients presented insidiously with symptoms similar to type 2 diabetes. Although siblings in the same families had the same m.3243A $>$ G mitochondrial DNA mutation, the clinical manifestations were different. In family II, the sister presented with diabetes and deafness, whereas the brother had diabetes and deafness and also presented with MELAS (mitochondrial encephalomyopathy with lactic acidosis and stroke-related episodes). Therefore, to properly diagnose mitochondrial diabetes, understanding the profiles of the clinical presentations of the disease is very important.

Heteroplasmy levels lead to varying clinical phenotypes in different tissues $[19,20]$. In patients with mitochondrial diabetes, mitochondrial dysfunction in beta cells causes insulin secretion disorder [21, 22], imbalance of ion concentrations, and cell death within the vascular stria that leads to reduction in sound transduction [23]. Direct PCR and sequencing analysis (Sanger sequencing) are widely available and simple methods for detecting m.3243A $>$ G mitochondrial DNA mutation. Although the peak height $G$ to $A$ ratio does not represent the real value of heteroplasmy levels, it is widely used for detecting point mutation in disease diagnosis. This study found that the peak height $G$ to A ratio was negatively associated with age at the onset of mitochondrial diabetes, that the ratio was higher, and that age at the onset

Table 6 Correlation analysis between leukocyte telomere length and FBG, HbA1c, fasting C-peptide, fasting insulin, HOMA-IR index and HOMA-IS index, and the peak height $G$ to $A$ ratio

\begin{tabular}{lcl}
\hline & Correlation coefficient r & $P$ \\
\hline Fasting blood glucose & 0.282 & 0.374 \\
HbA1C & 0.014 & 0.965 \\
Fasting C-peptide & 0.332 & 0.292 \\
Fasting insulin & 0.243 & 0.463 \\
HOMA-IR & -0.127 & 0.694 \\
HOMA-IS & 0.253 & 0.427 \\
the peak height G to A ratio & -0.156 & 0.646 \\
\hline All data were analyzed after correction for age and duration of disease. All
\end{tabular}

All data were analyzed after correction for age and duration of disease. All data were analyzed using Pearson correlation analysis of the disease was younger. The peak height $\mathrm{G}$ to $\mathrm{A}$ ratio depended on m.3243A $>$ G mitochondrial DNA mutation heteroplasmy levels, according to the research conducted by Laloi-Michelin et al. [23]. The results suggested that although Sanger sequencing is not a quantitative method compared with site-specific quantitative PCR, it could be a simple method for indicating, to some extent, the degree of severity of mitochondrial diabetes in clinical work.

Different m.3243A $>$ G mitochondrial DNA mutation heteroplasmy levels result in varying energy metabolism disorders of mitochondria [24]. The mechanism of diabetes is complicated. Mitochondrial diabetes caused by monogenic mutation is an ideal model for investigating the pathogenesis of diabetes. Mitochondria, which are an essential component of energy production through oxidative phosphorylation (OXPHOS), have a close relationship with cellular senescence. Mitochondria generate a large amount of reactive oxidative species (ROS) as a toxic by-product of OXPHOS, which plays an important role in telomere shortening [25]. Mitochondrial dysfunction caused by DNA mutations is observed in mitochondrial dysfunction in the pancreas has an impact on beta cell secretion function in patients with mitochondrial diabetes [21, 22]. Telomere length can most likely be associated with the lifespan of beta cells, which is related to the secretion function of beta cells. To the best of our knowledge, this study is the first to investigate telomere length in patients with mitochondrial diabetes. This study found that compared with healthy controls, telomere length was shorter in patients with mitochondrial diabetes, which indicated that telomere length shortening likely participates in the pathogenesis of mitochondrial diabetes; however, when compared with type 2 diabetes, there was no significant difference; thus, telomere length is not specific to mitochondrial diabetes. This study investigated the correlation between telomere length, peak height $\mathrm{G}$ to A ratio, and blood glucose condition and noted that there was no significant difference between these variables. These observations suggest that telomere length is affected by many factors (higher BMI [26]) other than ROS; however, we cannot rule out the impact of the small sample size in the present study.

In this study, the number of patients with mitochondrial diabetes using insulin and oral hypoglycemic medications is equal, but the five probands all received insulin treatment at the very beginning of diabetes, which indicated worse beta cell function. An energy metabolism disorder exists in mitochondrial diabetes and is usually accompanied by elevated blood lactate levels; thus, to avoid lactic acidosis, oral hypoglycemic medications, such as metformin, should not be used [26]. In view of this risk, it is important to differentiate mitochondrial diabetes from type 1 or type 2 diabetes. 


\section{Conclusion}

Deafness with definite maternal inheritance, normal BMI, and elevated blood lactic acid and encephalomyopathy, for the most part, suggests the diagnosis of mitochondrial diabetes. According to Sanger sequencing, the peak height G/A ratio could reflect the spectrum of age at the onset of the disease and might therefore provide a prediction regarding the age of onset in particular cases. Telomere length was shorter in mitochondrial diabetes and type 2 diabetes, which suggests that telomere length shortening is likely involved in the pathogenesis of diabetes; however, it was not specific for mitochondrial diabetes. Our study also had some limitations, the study included very limited patient population and the heteroplasmy levels were detected in blood instead of urine. Therefore, in future, further, larger and better designed studies focused on the topic are still needed to draw more definitive conclusions.

\section{Competing interests}

All the authors declare that there is no conflict of interest that could be perceived as prejudicing the impartiality of the research reported.

\section{Authors' contributions}

$M C Z$ carried out the studies and drafted the manuscript. $R M$ measured the telomere length. JJ J, S Z, AL T, JP X participated in the design of the study. $Z Y L, H B Z, Y X L$ performed the statistical analysis. All authors read and approved the final manuscript.

\section{Acknowledgments}

We thank all of the subjects who participated in the study.

\section{Funding}

Project supported by National Natural Science Foundation of China (grant no. 81270878) and National Key Program of Clinical Science of China.

\section{Author details}

${ }^{1}$ Department of Endocrinology, Key Laboratory of Endocrinology, Ministry of Health, Peking Union Medical College Hospital, Beijing 100730, China. ${ }^{2}$ Hongshan Traditional Chinese Medicine Hospital, Chifeng City, Inner Mongolia 024076, China. ${ }^{3}$ Metabolic Disease Hospital of Tianjin Medical University, Tianjin City 300000, China. ${ }^{4}$ Nanyang City Center Hospital, Nanyang City, Henan 473003, China.

Received: 28 October 2014 Accepted: 30 September 2015 Published online: 08 October 2015

\section{References}

1. Goto Y-I, Nonaka I, Horai S. A mutation in the tRNA Leu(UUR) gene associated with the MELAS subgroup of mitochondrial encephalomyopathies. Nature. 1990;348:651-3.

2. Chae $\mathrm{H}$, Hwang H, Lim BC, Cheong HI, Hwang YS, Kim KJ. Clinical features of A3243G mitochondrial tRNA mutation. Brain Dev. 2004;26:459-62.

3. Verma A, Moraes C, Shebert R, Bradley W. A MERRF/PEO overlap syndrome associated with the mitochondrial DNA 3243 mutation. Neurology. 1996:46:1334-6.

4. Van den Ouweland J, Lemkes H, Ruitenbeek W, Sandkujl L, de Vijlder M, Struyvenberg $P$, et al. Mutation in mitochondrial tRNA Leu(UUR) gene in a large pedigree with maternally transmitted Type 2 diabetes and deafness. Nat Genet. 1992;1:368-71.

5. Naing A, Kenchaiah M, Krishnan B, Mir F, Charnley A, Egan C, et al. Maternally inherited diabetes and deafness (MIDD): Diagnosis and management. J Diabetes Complications. 2014;28(4):542-6.

6. Maassen J, Janssen G, t'Hart LM. Molecular mechanisms of mitochondrial diabetes (MIDD). Ann Med. 2005;37:213-21.
7. Zhao J, Miao K, Wang H, Ding H, Wang DW. Association between telomere length and type 2 diabetes mellitus: a meta-analysis. PLoS One. 2013;8:e79993.

8. Harte AL, da Silva NF, Miller MA, Cappuccio FP, Kelly A, O'Hare JP, et al. Telomere length attrition, a marker of biological senescence, is inversely correlated with triglycerides and cholesterol in South Asian males with type 2 diabetes mellitus. Exp Diabetes Res. 2012;2012:895185.

9. Zee RY, Castonguay AJ, Barton NS, Germer S, Martin M. Mean Leukocyte telomere length shortening and type 2 diabetes mellitus: a case-control study. Transl Res. 2010;155:166-9.

10. Salpea KD, Talmud PJ, Cooper JA, Maubaret CG, Stephens JW, Abelak K, et al. Association of telomere length with type 2 diabetes, oxidative stress and UCP2 gene variation. Atherosclerosis. 2010;209:42-50.

11. Kurz DJ, Decary S, Hong Y, Trivier E, Akhmedov A, Erusalimsky JD, et al. Chronic oxidative stress compromises telomere integrity and accelerates the onset of senescence in human endothelial cells. J Cell Sci. 2004;117:2417-26.

12. Liu L, Trimarchi JR, Smith PJ, Keefe DL. Mitochondrial dysfunction leads to telomere attrition and genomic instability. Aging Cell. 2002;1:40-6.

13. Passos JF, Saretzki G, von Zglinicki T. DNA damage in telomeres and mitochondria during cellular senescence: is there a connection? Nucleic Acids Res. 2007;35:7505-13.

14. Cawthon RM. Telomere length measurement by a novel monochrome multiplex quantitative PCR method. Nucleic Acids Res. 2009;37:e21.

15. Chinnery PF, Zwijnenburg P, Walker M, Howell N, Taylor R, Lightowlers RN, et al. Non-random tissue distribution of mutant mtDNA. Am J Med Genet. 1999:85:498-501.

16. Narbonne H, Perucca-Lostanlen D, Desnuelle C, Vialettes B, Saunieres A, Paquis-Fluckinger $\mathrm{V}$. Searching for A3243G mito-chondrial DNA mutation in buccal mucosa in order to improve the screening of patients with mitochondrial diabetes. Eur J Endocrinol. 2001;145:541-2.

17. Wang S, Wu S, Zheng T, Yang Z, Ma X, Jia W, et al. Mitochondrial DNA mutations in diabetes mellitus patients in Chinese Han population. Gene. 2013;531:472-5.

18. Mancuso M, Orsucci D, Angelini C, Bertini E, Carelli V, Comi GP, et al. The m.3243A>G mitochondrial DNA mutation and related phenotypes. A matter of gender? J Neurol. 2014;261:504-10.

19. Zhang S, Tong AL, Zhang Y, Nie M, Li YX, Wang H. Heteroplasmy level of the mitochondrial tRNaLeu(UUR) A3243G mutation in a Chinese family is positively associated with earlier age-of-onset and increasing severity of diabetes. Chin Med Sci J. 2009;24:20-5.

20. Kadowaki H, Tobe K, Mori Y, Sakura H, Sakuta R, Nonaka I, et al. Mitochondrial gene mutation and insulin-deficient type of diabetes mellitus. Lancet. 1993;341:893-4.

21. Walker M, Taylor R, Stewart M, Bindoff L, Shearing P, Anyaoka V, et al. Insulin and proinsulin secretion in subjects with abnormal glucose tolerance and a mitochondrial tRNA Leu(UUR) mutation. Diabetes Care. 1995;18:1507-9.

22. Steel KP, Kros CJ. A genetic approach to understanding auditory function. Nat Genet. 2001;27:143-9.

23. Laloi-Michelin M, Meas T, Ambonville C. The clinical variability of maternally inherited diabetes and deafness is associated with the degree of heteroplasmy in blood leukocytes. J Clin Endocrinol Metab. 2009;94:3025-30.

24. Wallace DC. Mitochondrial genetics: a paradigm for aging and degenerative diseases? Science. 1992;256:628-32.

25. Du M, Prescott J, Cornelis MC, Hankinson SE, Giovannucci E, Kraft P, et al. Genetic predisposition to higher body mass index or type 2 diabetes and leukocyte telomere length in the Nurses' Health Study. PLoS One. 2013:8:e52240

26. Meas T, Laloi-Michelin M, Virally M, Ambonville C, Kevorkian JP, Guillausseau PJ. Mitochondrial diabetes: clinical features, diagnosis and management. Rev Med Interne. 2010;31:216-21. 